\title{
Production of renewable energy in agriculture: current situation and future developments
}

\author{
Carlo Pirazzoli, Alessandro Ragazzoni \\ Department of Agricultural Sciences, University of Bologna, Bologna, Italy
}

\section{Introduction}

In recent years there has been growing interest in the development of renewable energy due to the need to solve problems related to the increase in energy consumption and the instability of prices for raw materials of fossil origin, and because of concerns about pollution and the effects on climate change. In order to solve these problems there have been extensive studies to research systems and processes capable of limiting the increase in "greenhouse" and so-called "climate changing" gases and, at the same time, to make countries increasingly independent from the energy point of view.

In Italy, similar considerations have taken on a special significance, precisely because of the increasing dependence on foreign energy (equal to over 83\% in 2009) (For further details see "Rapporto energia e ambiente: analisi e scenari 2009 (Energy and Environment Report: Analysis and Scenarios 2009)" ENEA 2010), the cost of energy and emissions harmful to the climate, all running counter to the objectives laid down at international level on the subject of global warming.

To try to tackle these issues, there has been an increase in the need to promote efficient long-term energy planning and to provide adequate public incentives for technological innovation and research in the context of saving and improving energy efficiency and technical alternatives to the consumption of fossil fuels.

In particular, the ongoing climate change will require a greater commitment to take all possible measures to reach conditions of equilibrium and overall efficiency in the production and use of energy according to models of sustainability.

Faced with this scenario, the agricultural sector can also play an important role in contributing to increased production of energy from renewable sources. Climate-related problems are directing agriculture towards new challenges and new opportunities, specifically in relation to local presence that characterizes the strategic activities of the sector.

In addition, agriculture can contribute, also directly, to reducing net emissions of carbon dioxide $\left(\mathrm{CO}_{2}\right)$ and other greenhouse gases, both

Correspondence: Carlo Pirazzoli, Department of Agricultural Sciences University of Bologna, Italy. E-mail: carlo.pirazzoli@unibo.it

(C) Copyright C. Pirazzoli and A. Ragazzoni, 2013

Licensee PAGEPress, Italy

Journal of Agricultural Engineering 2013; XLIV(s2):e101

doi:10.4081/jae.2013.s2.e101

This article is distributed under the terms of the Creative Commons Attribution Noncommercial License (by-nc 3.0) which permits any noncommercial use, distribution, and reproduction in any medium, provided the original author(s) and source are credited. through the exploitation of various types of biomass for energy purposes, to be used as a substitute for fossil fuels, and through the adoption of agricultural practices that favour the accumulation of carbon in cultivated plants and the soil.

Indeed, the ability of plants to trap solar energy, converting and storing it permanently in the form of chemical energy is well known, as well as their ability to capture carbon dioxide from the atmosphere, retaining the carbon and emitting oxygen. Remember that in $1.0 \mathrm{~g}$ of dry matter there is about $0.5 \mathrm{~g} \mathrm{C}$ which is obtained from $1.83 \mathrm{~g}$ of fixed atmospheric C02 (D. Coiante, 2010).

Therefore, the role of agriculture in the field of energy is part of a wider framework of services that can it can provide to the community, integrating the concept of multifunctionality that has been attributed to it. Without forgetting that agricultural activity represents an excellent opportunity to protect and enhance the territory, the production of agro-energy could become an opportunity for farmers, who would find new outlets, not only for their crops, but also for by-products and agrolivestock waste/slurry.

In this regard it is noted that, in order to meet obligations under the Kyoto Protocol, as well as the latest EU energy plan, decisive action must be taken to expand the contribution of alternative sources to current overall energy needs with promotional actions aimed at taking advantage of all the opportunities that they offer. In fact, people are aware that there cannot be a single rapid replacement of existing energy resources with other more sustainable ones, and that the possible complementarity of new renewable energy sources (RES) must be studied in relation to the vocation of the territory in which its development is to be planned.

\section{Agro-energy production chains}

From the foregoing it can be said that energy production represents an important opportunity for farmers to diversify their business, broadening the prospects and scenarios for the agricultural and livestock farms.

The energy potential of a rural area through the use of biomass produced in by agricultural activity will now investigated in depth: we will therefore describe the agro-energy production chains using biomass specifically, while ignoring other technologies (primarily photovoltaic and solar thermal) that can be developed, even with a profit, by the farmer, but which are not directly related to the traditional activity of a farm.

Raw materials of agricultural origin can be destined mainly for the production of electricity, heat or biofuels depending on the intrinsic characteristics, following a variety of transformation processes. As shown in Figure 1 the main energy production chains that can be activated in a farm are as follows:

- Chain for production of solid biofuels (thermo-chemical conversion process);

- Chain for production of biofuels (physical-chemical conversion process);

Chain for production of Biogas (biological conversion process). 


\section{Solid biofuel production chain}

The activation of this chain is linked to certain physical and chemical characteristics of biomass. In particular, this raw material must have a relationship between carbon and nitrogen content (C/N ratio) with values greater than 30 (lignocellulosic biomass) and a low moisture content (less than $30 \%$ on a wet basis). The following raw materials are suitable for these specifications:

- crops dedicated to the production of solid biofuels, such as pluriennial tree species a with short rotation (Short Rotation Forestry SRF), including trees such as poplar, eucalyptus, acacia and willow; perennial herbaceous crops, such as the common reed, miscanthus and thistle;

annual herbaceous crops, including fibre sorghum, kenaf and hemp;

wood processing waste in the industrial sector;

felling and pruning in the urban sector;

copse, high forest, waste products from the use of high forests and intermediate cutting in the forestry sector;

- woody component of Municipal Solid Waste (MSW).

In the case of using dedicated crops, we remind you that, for the economic sustainability of the supply chain, the production of this biomass must be low-input (fertilizers, chemical defence products, mechanical energy, etc.) and using simplified cultivation models; the rapid development and the hardiness of these plant species usually do not justify intensive cultivation methods. The most important stage is harvesting, which must be carried out so as to obtain a low humidity product (less than $30 \%$ on a wet basis) and must be logistically well organized, in order to contain costs. Plant biomass for combustion has low energy density. Harvesting of wood chips, shredded sorghum, cane etc. provides a product with very low specific weight, with values of $0.35-0.5$ $\mathrm{t} / \mathrm{m}^{3}$. A unit of volume of the harvested product is composed, therefore, of more than $50 \%$ air. The remaining organic portion is composed of at least $50 \%$ of water, for which the cost of transportation per unit of dry matter becomes very high. Furthermore, the low specific weight of the product does not allow maximum capacity of lorries to be reached, increasing the amount of transport necessary per unit of area.

Lignocellulosic biomass intended for direct combustion for the production of heat, before being placed on the market, generally undergoes a more or less complex process of transformation to impart the necessary physical and energy characteristics. The main commercial forms for this category of biomass are:

- firewood (blocks or logs),

- wood chips,

- pellets and briquettes.

Direct combustion exclusively for generation of thermal energy is performed in thermal boilers available on the market with multiple technical solutions (reverse flame boilers, boilers with fixed or mobile grid, boilers with automated loading).

The heat produced may also be used for heating the water circulating in a circuit of pipes. In this way it is possible to heat various environments (up to entire buildings, depending on the size of the plant) using a single boiler. Waste heat recovery significantly improves the energy balance of the system.

It is also possible to produce electricity by expanding steam in a turbine. In this way it is possible to convert thermal energy into electrical energy with an efficiency of 15-38\%. Also for this type of energy production there are different technologies that can recover heat from the entire volume of steam produced (backpressure systems) or only from a fraction of the steam (condensing and bleeding systems).

Direct combustion results in technology that is a quite widespread despite its low energy yields, production of potentially hazardous fumes due to the presence of carbon monoxide ( $\mathrm{CO}$ ), oxides of sulphur and

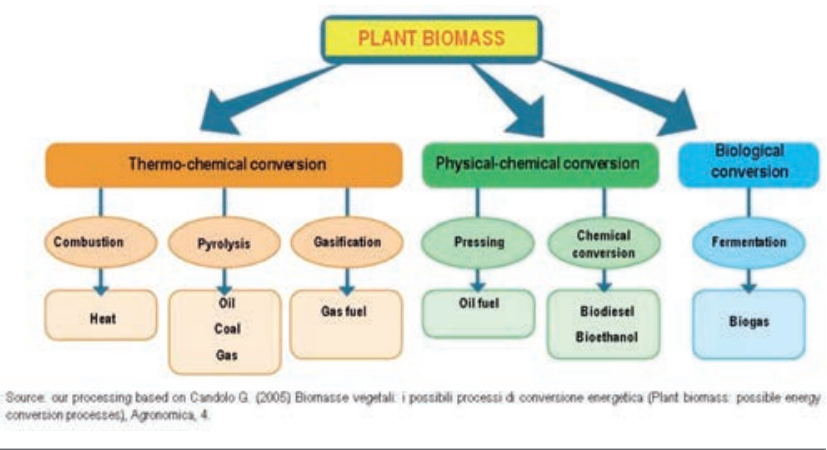

Figure 1. Energy production chains using agro-livestock biomass.

nitrogen $\left(\mathrm{SO}_{\mathrm{x}}\right.$ and $\left.\mathrm{NO}_{\mathrm{x}}\right)$, as well as problems regarding management of the ashes. Gasification and pyrolysis have an efficiency that is $30-35 \%$ greater than combustion, but the complex technology and difficult purification of the gas produced have greatly limited the spread of these types of systems.

A Ministerial Decree was recently was recently released on thermal energy and energy efficiency (Ministerial Decree 28 December 2012) favouring families and public administrations. In particular, this incentive covers at least $40 \%$ of the investment and will be provided over two years (five for more costly operationsi).

This measure is an essential step in order to achieve and exceed the European environmental targets for 2020, especially with regard to the quota of thermal energy, for which Italy is still very deficient.

The decree, in fact, sets itself the dual purpose of boosting the production of thermal energy from renewable sources (biomass heating, heat pumps, thermal solar) and accelerating projects for upgrading the energy efficiency of public buildings.

On renewable thermal sources, the new incentive system will promote small scale interventions, typically for domestic and small business use, including greenhouses, which until now have not been encouraged by supporting policies. In this study, it was decided not to investigate this sector any further because:

the legislation is very recent and still poorly implemented;

the business reference framework adopted refers to medium-large scale operations and the amount of biomass produced is significant, and would therefore require the possibility of installing greater power.

\section{Biofuel production chain}

The physical-chemical conversion of biomass into biofuels requires the prevalent use of dedicated crops (and to a lesser extent of agroindustrial waste) for the production of fuels intended to replace, at least in part, petrol and diesel derived from oil. Despite the many benefits resulting from the use of these biofuels (use of renewable raw material, less dependence on fossil fuels etc.), this energy sector has had limited development in Italy because of very high production unit costs, which prevent biodiesel and bioethanol from competing with fossil fuel. Also, to make matters worse, large expanses of arable land would need to be found in order to meet the current demand for fuel, resulting in radical changes in the traditional destination of food crops. For these reasons, much of public opinion has strongly criticized the development of this technology, which now seems limited exclusively to the presence of a specific financial incentive and a production quota exempt from public excise duty.

The chain in question is classified according to the end product of the physical-chemical conversion of the biomass, namely: 
pure vegetable oils;

biodiesel;

bioethanol.

The term pure vegetable oils refers to crude or refined oils produced from oilseeds by pressing or extraction, but not modified from a chemical point of view. Their properties as liquid biofuels, intended for direct combustion in place of diesel fuel, depend on the dedicated crop used. The main oil producing species grown in Italy are sunflower, canola and soybeans, while globally the majority of oil production comes from the palm.

Biodiesel is a liquid fuel, consisting of a mixture of methyl esters, obtained through the trans-esterification (Transesterification is a chemical reaction in which the alcohol group of an ester is replaced by that of another alcohol) of vegetable oils or other raw materials rich in lipids. This biofuel is suitable for replacing fuel in the Diesel cycle engines widely used in the transport sector. In conventional diesel engines, however, it must be mixed with diesel fuel up to a maximum of $30 \%$ in volume. Use it in pure form, on the other hand, requires specific technology.

The crops used in the supply chain of biodiesel are the same as those for pure vegetable oils, but animal fats of agro-industrial origin can be used as an alternative, as can cultivations of single-cell eukaryotic algae and/or prokaryotic cyanobacteria, which have a high lipid content, approximately $80 \%$ dry matter. The use of the latter type of raw material is still quite experimental, but presents numerous advantages dictated by the speed of growth of the algae and the yield per surface area much higher than traditional crops.

Finally, bioethanol is a liquid biofuel, obtained from the alcoholic fermentation of biomass (plant-based where dedicated crops are used and agri-forestry or animal residues in the case of animal manure) and/or the degradable part of waste (FORSU - agro-industrial residues) and is suitable for replacing petrol in the transport sector.

The main Italian alcohol producing crops that can be used for the production of bioethanol are sugar beet and sorghum due to the high content of simple sugars in the roots and stalks, and maize and wheat for the abundant presence of starch in the grains. In the international arena, however, the production of bioethanol derives primarily from sugar cane.

In conclusion, it can be argued that it is difficult to achieve an organized chain in Italy that would allow biofuels to be produced from domestic raw material: the goal of reaching at least $10 \%$ of transport consumption is almost impossible and the multinational oil companies currently find it more economically viable to import finished or semifinished products from other countries where the availability of dedicated crops is greater and industrial processing has been established for some time (primarily, South America and Eastern European countries).

\section{Biogas production chain}

The term biogas refers to a mixture of gases, consisting primarily of methane (50-80\%), obtained from the anaerobic fermentation of biomass of plant and animal origin.

This process occurs is performed by microorganisms capable of metabolizing the organic substance with consequent production of gas. Compared to the previously described production chains, that of biogas involves the development of active microorganisms, for which reason it is essential to achieve living conditions optimal for them, and to maintain over time.

The raw materials involved in the biological conversion process are as follows:

Energy crops: such crops, referred to as "dedicated" to energy conversion, are essentially maize, sorghum, triticum, wheat, rye, etc.
These are materials with high dry matter content and a high yield in biogas.

Manure: this biomass has particular importance in the biogas production process because it waste that can be exploited, and it also involves a large amount of micro-organisms which act as inoculum in the transformation of the substrate into biogas. Effluents do not normally have high yields, also due to the small proportion of organic matter ( $<10 \%$ of total).

- Crop residues: these refer to residues from agricultural production such as maize stalks, straw, fruit waste, etc.. It is a material with a good biogas yield, but with variable characteristics that require specific analysis.

- Agro-industrial by-products: this is organic waste matter that is commonly produced in the processing of food products. In particular, it includes slaughter waste, residues from the production of juices, molasses, whey, and so on. These substrates have a high potential, but may be subject to seasonal availability or specific authorizations (such as slaughterhouse waste) (The use of slaughterhouse waste for energy purposes is regulated by specific permits issued by the Veterinary Service on the basis of EC Regulation 1774/2002).

- Organic fraction of municipal solid waste: this category includes numerous materials, difficult to classify and usable only on the basis of the directives on "waste".

Regarding the technology used, the main distinctions concern the total solid content in the biomass used and the temperature of the process (Navarotto, 2010). Digestion, therefore, can be defined as "wet", if the substrate has a total solid content less than $10 \%$ and "dry" if the percentage is greater than $20 \%$. In the first case, the material used can be mixable and pumpable, while in the second case, the substrate is not mixable and special techniques are required for loading the plant (For further detials see: Ragazzoni A. (2011), BIOGAS Normative e biomasse: le condizioni per fare reddito, Edizioni L'Informatore Agrario, Verona). As regards the process temperatures, fermentation can be mesophilic, when the temperatures are kept between 38 and $40^{\circ} \mathrm{C}$, thermophilic (between 55 and $57^{\circ} \mathrm{C}$ ) or in psychrophilic (below $35^{\circ} \mathrm{C}$, but this is uncommon). For each temperature different families of microorganisms develop and suitable for carrying out the digestion process.

Typically a wet digestion biogas plant with mesophilic operation, consists of one or more fermentation tanks made of steel or reinforced concrete equipped with an internal heating system, a biomass mixing system and a gasometric covering capable of accumulating the biogas produced. A system of pipes delivers the gas to a purification complex, normally a chiller (or refrigerator) with a heat exchanger, for the elimination of the water vapour, and subsequently to an internal combustion engine for the production of electricity. The motors used are able to recover the thermal energy deriving from the cooling system in order to heat the fermentation tanks and possibly other production premises or dwellings; in this case, the process is referred to as cogeneration.

The end product of the anaerobic digestion process is the digestate, which takes the form of stabilized organic matter (generally odourless) with organic and chemical characteristics derived from the substrate used as input to the system.

The production of biogas is currently of great interest to the agricultural sector. The ability to use different organic substrates, the characteristics of the digestate (suitable as a soil conditioner and fertilizer) and the current incentive system, make this type of chain one of the most widespread agro-energy technologies in the country.

Faced with a proven technology, the main problems with this energy chain are to be found in the procurement of the biomass, costs for transport and management of the biomass and digestate and in the regulatory framework which is often difficult to interpret at the local level. 
As mentioned, the current incentive rate of 0.28 euro/ $/ \mathrm{kWh}$ of electricity fed into the grid (valid for plants built and in operation by $31 / 12 / 2012$ ) has enabled the activation of large-scale power plants, also in those cases where it was difficult to procure supplies of the biomass necessary for the process, where most of it was purchased on the market and not produced directly on the farm. In these cases, the economic vulnerability of the plants increases, since their sustainability depends economic parameters, which are unlikely to remain stable over time (rental cost of land, cost of the substrates on the market, costs for disposal of the digestate etc.), which must be considered to be at least 15 years, based on the limits for issuing incentive grants. On the basis of these considerations, and with the current reduction in the comprehensive rate, increasing attention has been focussed on the exploitation of waste raw materials to feed the digesters, and to size these according to the actual availability of substrates.

The biogas chain will be examined in more detail below, which has in recent years acquired an important role in rural areas, especially in relation to the significant growth in the number of plants constructed (Figure 2).

\section{Reference standards}

The production of energy from biogas is subject to a complex legislative framework that is not always easy to interpret. This chapter summarizes the main aspects that regulate this energy chain, with reference to the legislation that authorizes and incentivises plants at national level (Figure 3); in particular, the examination looks at::

authorization procedure;

tax issues relating to the activity of energy production;

agrifood by-products;

incentives for the production of renewable electricity (with partic-

ular reference to the Ministerial Decree of 6 July 2012).

\section{Plant authorization procedure}

The guidelines for authorization to construct and operate plants producing electricity from renewable sources were published in the Official Journal of 18 September, 2010 and inserted definitively in Legislative Decree no. 28 (Legislative Decree no. 28 of 3 March, 2011
Implementation of Directive 2009/28/EC on the promotion of energy from renewable sources, amending and subsequently repealing Directives 2001/77/EC and 2003/30/EC) of 3 March, 2011, which implements the basic Directive 2009/28/EC (Directive 2009/28/EC of the European Parliament and of the Council of 23 April 2009 on the promotion of energy from renewable sources and amending and subsequently repealing Directives 2001/77/EC and 2003/30/EC (Official Journal of the European Union 05/06/2009)) on the promotion of renewable energy. The authorization process, followed by all the Italian Regions, provides the following reference framework:

a. systems considered as freely constructed and subject to simple communication: in the case of installed electrical power $<50 \mathrm{~kW}$ in a cogeneration scenario, or $<200 \mathrm{~kW}$ if the property structure of the buildings is not changed;

b. plants that can be constructed through a simplified enabling procedure when the installed electrical power is $<250 \mathrm{~kW}$, or $<1 \mathrm{MW}$ in the case of cogeneration with heat recovery;

c. installations subject to a single authorization in all other cases.

Plants are, therefore, classified according to the installed power and cogeneration capacity, but the innovation in the Legislative Decree concerns the simplification of procedures introduced in an attempt to speed up the authorization process.

\section{Taxation of energy production}

An important element for the economic evaluation the activity in question is the incidence of the tax burden. Art. 1 para. 369 of the 2007 Finance Act (Law no. 296/06) states that «(...) the production and sale of electric and heating power from renewable agroforestry sources (...) constitute related activities pursuant to Article 2135, third paragraph, of the Italian Civil Code and are considered as producing agricultural income». In this case, they involve taxation on a cadastral basis of limited importance for the balance sheet of the agro-energy business. The concept of related activity is linked to the principle of prevalence (The principle can be satisfied according to the quantitative requirements (products used in performing related activities obtained from agricultural activity on the farm are prevalent compared to those purchased from third parties) or value (the value of the products obtained from agricultural activity is higher than the cost incurred to purchase thirdparty products). If neither of the two parameters can be adopted, as in the case of animal slurry, prevalence can be detected by a comparison

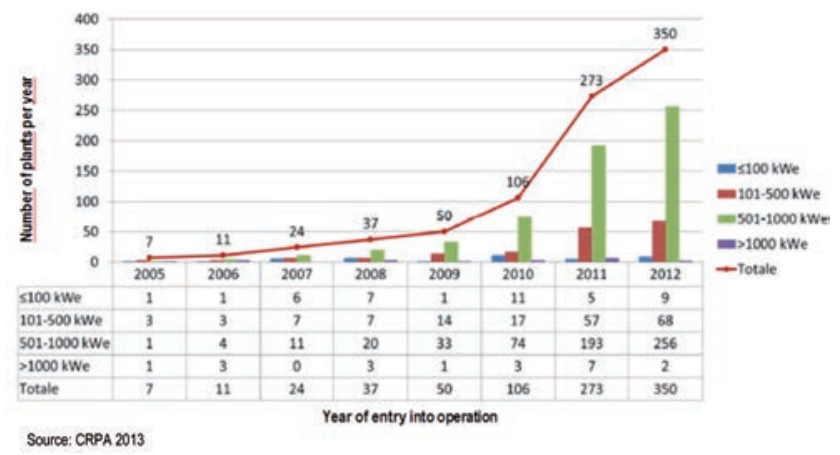

Figure 2. Dynamics of the construction of biogas plants in Italy.
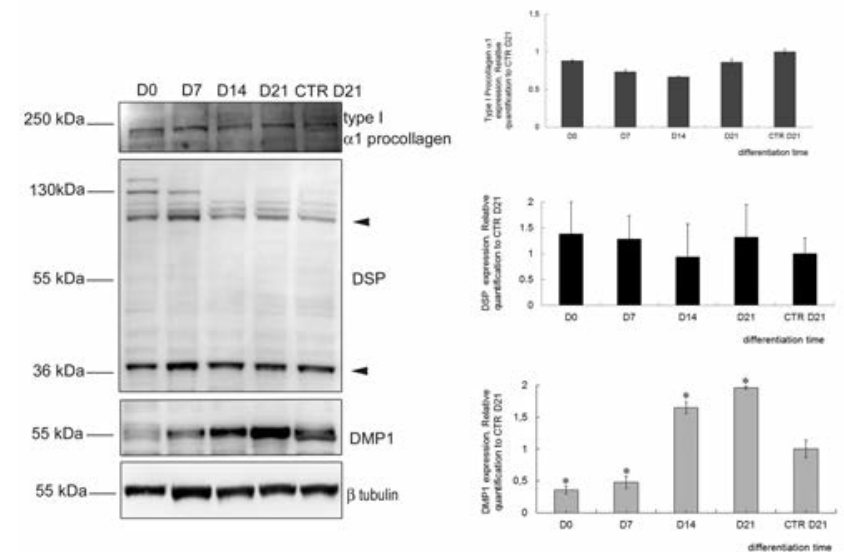

Figure 3.- Key regulatory elements for designing a biogas plant. 
between the energy deriving from its own products and that derived from products purchased from third parties), according to which products must derive primarily from the main activities or from the use of equipment and/or resources normally used in the business. This taxation on plants has also been maintained in the latest regulatory references for projects that will require authorisation after 31/12/2012.

\section{By-products of organic and agro-livestock origin}

Regarding the raw material that can be used for the production of biogas, some recent regulatory specifications have attempted to provide greater clarity. In particular, these include Ministerial Decree no. 205 of 3 December, 2010 and Legislative Decree No. 28 of 3 March 2011 that have better defined the applicability of Legislative Decree no. 4 of 16 January, 2008 on the "definition of by-product".

In essence, the new interpretation amends Part IV of Legislative Decree no. 152/2006 (Environmental Regulations), in Article 183, paragraph 1, letter qq) and defines a by-product, and not waste (pursuant to Article 183, paragraph 1, letter a) as any substance or object that satisfies the conditions and criteria specified by Article 184-bis, paragraphs 1 and 2 :

a) the substance or the object originated from a production process, of which it forms an integral part, and the primary purpose of which is not the production of such a substance or object;

b) it is certain that the substance or object will be used, during the same or a subsequent production or use process, by the manufacturer or by a third party;

c) the substance or object can be used directly without any further processing other than normal industrial practice;

d) further use is lawful, in other words, the substance or object fulfils, for the specific use, all the relevant requirements regarding the products and the protection of health and the environment and will not lead to overall adverse impacts on the environment or human health.

The new draft, therefore, of the aforementioned Article 183 states that: «...by-products include (...): faecal and plant material from cuttings and pruning as part of the maintenance of public and private green areas, or from agricultural activities, which are used in agricultural activities, even outside the place of production, or sold to third parties or used for company inter-corporate plants for the production of energy or heat, or biogas...».

The digestate obtained from third party manure will retain the pos-

Table 1. Basic incentive rates for 2013 and premiums established by the Decree.

\begin{tabular}{|c|c|c|c|c|c|c|}
\hline \multicolumn{3}{|c|}{ BASE INCENTIVE } & \multicolumn{4}{|c|}{ ADDITIONAL PREMIUIAS } \\
\hline \multirow[t]{2}{*}{$\begin{array}{l}\text { Type of diet } \\
\text { used }\end{array}$} & Peserer & $\begin{array}{c}\text { Base } \\
\text { incentive } \\
\text { mete } \\
2013 \\
\text { for } 20 \text { years } \\
\end{array}$ & 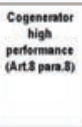 & 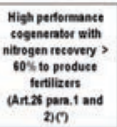 & 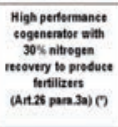 & 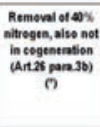 \\
\hline & $\mathrm{kW}$ & euro/kWh & eurolkWh & eurakWh & euralkWh & eurakWh \\
\hline \multirow{5}{*}{$\begin{array}{l}\text { Products of } \\
\text { biological } \\
\text { origin }\end{array}$} & $1<P \leq 300$ & 0.180 & 0.040 & 0.030 & 0.020 & 0.015 \\
\hline & $301<P \leq 600$ & 0.160 & 0.040 & 0.030 & 0.020 & 0.015 \\
\hline & $600<P \leq 1,000$ & 0.140 & 0.040 & 0.030 & ... & $\ldots$ \\
\hline & $1,000<P \leq 5,000$ & 0.104 & 0.040 & 0.030 & ... & $\ldots$ \\
\hline & $P>5,000$ & 0.091 & 0.040 & 0.030 & $\ldots$ & $\ldots$ \\
\hline \multirow{5}{*}{$\begin{array}{l}\text { By-products } \\
\text { of biological } \\
\text { origin (") }\end{array}$} & $1<P \leq 300$ & 0.236 & 0.010 & 0.030 & 0.020 & 0.015 \\
\hline & $301<P \leq 600$ & 0.206 & 0.010 & 0.030 & 0.020 & 0.015 \\
\hline & $600<P \leq 1,000$ & 0.178 & 0.010 & 0.030 & ... & $\ldots$ \\
\hline & $1,000<P \leq 5,000$ & 0.125 & 0.010 & 0.030 & $\ldots$ & $\ldots$ \\
\hline & $P>5.000$ & 0.101 & 0.010 & 0.030 & $\ldots$ & ... \\
\hline
\end{tabular}

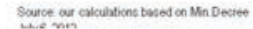

sibility for agronomic use integrally, because it derives from by-products and not from waste, naturally always in compliance with the obligations under the Nitrates Directive (Council Directive 91/676/EEC of 12 December 1991 concerning the protection of waters against pollution caused by nitrates from agricultural sources, implemented by the DM 7 April 2006).

\section{Incentives and tariffs for energy production activity}

Crucial elements among the decisive factors for the activation of a plant are the value and duration of financial incentives for the production of energy produced and sold to the network operator. This paragraph describes the procedures that apply the provisions of Ministerial Decree 6 July 2012: "Implementation of Art. 24 of the Legislative Decree no. 28 of 3 March, 2011 establishing incentives for the production of electricity by plants using renewable sources other than photovoltaic".

The new incentive system for the production of electricity from renewable sources, as well as providing a mechanism for gradual reduction of the incentive level (Art. 7 comma 1 (..) for plants that come into operation in the years after 2013, the value of base incentive tariffs is reduced by $2 \%$ per year, with commercial rounding to three decimal places (...)), is also characterized by the introduction of a maximum annual funding quota (5.8 billion euro per year) and the available power of incentivised energy (The definition of these quotas has the function of protecting consumers and users by limiting increases in costs on electricity bills, the proceeds of which finance the promotion of renewable energy) (Table 1). The Decree provides for two types of incentives:

a comprehensive incentive tariff (To) for plants with power $<1$ MW;

an incentive (I) for plants with power $>1 \mathrm{MW}$ and for those with power not exceeding $1 \mathrm{MW}$ that do not opt for the all-inclusive rate, calculated as the difference between a fixed value (total revenue) and the time zone price of the energy (referring to the zone where the electricity produced by the plant it is fed into the grid).

As regards the biomass used, the classes of incentives indicate a desire to reward projects that use, above all, agri-livestock and agroindustrial by-products as substrates, as well as the organic fraction of the waste (in a non-agricultural context), compared to plants designed for the use of "products" (as defined by the regulations) and, therefore, of crops dedicated to energy conversion (specifically, for example, grain silage). In this way, process waste matrices will be better exploited, while it is conceivable that projects related to the exclusive or priority use of dedicated crops will decrease.

As mentioned previously, the other distinguishing feature introduced with the new Decree, is the "size" of the system, understood as the installed electrical power. Five classes have been identified to which different tariffs are applied for the electricity produced and provided. The most important classes for the agricultural refer to power plants included in the category: $1 \leq 300 \mathrm{~kW}$, those in the range $300 \leq$ $600 \mathrm{~kW}$ and thirdly, $600 \leq 1,000 \mathrm{~kW}$.

The most important classes for the agricultural refer to power plants included in the category: $1 \leq 300 \mathrm{~kW}$, those in the range $300 \leq 600 \mathrm{~kW}$ and thirdly, $600 \leq 1,000 \mathrm{~kW}$. The introduction of so-called "bonuses" for cogeneration, for the removal of nitrogen and for the containment of emissions, as well as achieving desirable targets for energy and environmental efficiency, also contribute to a further selection criterion for plants, based on the profitability that can potentially be obtained by integrating the various processes. This mechanism seems respond more to business figures who make investments within a complementary framework with local resources and with the need to protect the territory, in reality limiting the spread of initiatives that may, however, be considered as unsustainable (such as high power biogas plants pow- 
ered exclusively by maize and concentrated in small areas).

The duration of the new incentives, as defined in Annex 1 of the Decree, is extended to 20 years (compared with the 15-year period up to 2012), in order to provide greater guarantees of stability of profits for the entrepreneur and a longer life time for the plant, so that it will not require final decommissioning after the end of the incentives, but will be allowed to continue operating.

Lastly, the Decree, finally, defines three different modes of access to the incentive mechanisms, depending on the power, which for biogas plants (new, fully rebuilt, re-activated, undergoing renovation or upgrading) are:

direct access in the case of plants with power $<100 \mathrm{~kW}$

entry in Registers in the case of plants between $100 \mathrm{~kW}$ and $<5,000$

$\mathrm{kW}$;

competitive downward auction procedures, if the power is $>5,000$ $\mathrm{kW}$.

\section{Assessments on the economic sustainability of biogas production plants.}

The analysis of the cost-effectiveness of an anaerobic digestion plant for the production of biogas for energy purposes includes certain important decisions that the entrepreneur must face in the design phase: which organic matrices to use for the operation of the digester? What economic advantage can be gained in choosing one "diet" over another? What is the optimum power of the plant?

The uncertainty surrounding the answers and the risk involved in the management decisions of the entrepreneur are not easily solved since there is no single analytical model that can be transferred to all rural contexts and to all businesses. However, we must start from certain basic assumptions: first, that the agro-energy chain must be sustainable from the environmental, territorial and economic point of view. For this purpose, the regulations that are periodically updated and approved at Community, national and local levels must be carefully observed.

The main objective is to chart an analytical path for assessing the economic viability of producing energy from biogas by identifying the elements that the agricultural entrepreneur needs to consider in the decision-making process, especially in light of the new incentive rates promoted by the Ministerial Decree of 6 July, 2012.

To this end, we have identified and explored some useful elements for business choices, which we believe to represent fundamental "nodes" for the approach of the entrepreneur designing a plant for the production of biogas and electricity.

\section{Elements for the evaluation of a plant for the production of biogas}

The analysis of the cost-effectiveness of an anaerobic digestion plant for the production of biogas and thermal and electrical energy is detailed and complex. The importance must be stressed of all the stages that characterize the supply chain: from the production of biomass, to transportation, construction and operation of the plant, the production and sale of electricity and thermal energy, and up to the management and transport of the final digestate.

In addition, new regulatory proposals relating to the value of the incentives as regards the all-inclusive tariff outline the analytical path that will be followed. In particular, the distinction of the rates on the basis of "power" and "diet" requires the valuation model to be set up distinguishing projects by the two categories of biomass that are of most relevance to agricultural enterprises (products or by-products of biological origin) and for two power ranges (from $1 \mathrm{~kW}$ to $300 \mathrm{~kW}$, and from $301 \mathrm{~kW}$ to $999 \mathrm{~kW}$ ). Therefore, attention will be focused on the four categories of plant resulting from crossing these two variables.

The goal is to verify how costs are distributed by enterprise and, consequently, to outline an economic-profitability framework applicable to different businesses in the biogas sector, according to new specifications for incentive rates. To grasp more clearly the significance of the results obtained from the calculations, it is necessary to specify the basic assumptions used, remembering that the indicators will be expressed in euro/kWh of electricity produced and sold:

1) the dynamics of growth of installed power is included in the range between $100 \mathrm{~kW}$ and $999 \mathrm{~kW}$;

2) the crop cost of the biomass from dedicated crops is estimated at around 1,750 euro/ha (based on direct surveys in areas of the Po Valley). To calculate the impact of the spending per unit of electricity produced we adopted the following parameters:

\section{average energy yield of biomass: $333 \mathrm{kWh} / \mathrm{ton}$;}

- average yield of maize silage: 55 ton/hectare.

Therefore, the cost is equal to: $1,750$ (euro/ha) / (55 ton/ha $333 \mathrm{kWh} / \mathrm{ton})=0.096 \mathrm{euro} / \mathrm{kWh}$

3 ) the cost of cultivation of biomass was increased in the case where conditions of business self-sufficiency do not exits; it is therefore assume that external land will be obtained with rental agreements to achieve some positive effects on the operation of the plant: the first is to limit external purchasing of biomass, which is certainly subject to the volatility of grain prices; the second is at the same time to meet the minimum requirement necessary so that energy production will be classed as a related activity and, therefore, subject to reduced agricultural taxation (self-production of raw material by the business must be at least $>50 \%$ );

4) external supply has been set with incremental quotas of $5 \%$ for each additional $90 \mathrm{~kW}$, starting from $100 \mathrm{~kW}$. In terms of value, the land rental cost could, for example, be at a cost of 750 euro/ha equal to:

$(750.00$ euro/ha $/ 55 \mathrm{t} / \mathrm{ha}) / 333(\mathrm{kWh} / \mathrm{t})=0.040(\mathrm{euro} / \mathrm{kWh})$

This additional portion of expenditure must be factored into the cost of cultivation, and therefore for biomass produced on leased land, the total cost becomes:

$0.096($ euro/kWh $)+0.040($ euro/kWh $)=0.136($ euro/kWh $)$

5) the transport of biomass entering and digestate leaving the plant is based on assumptions of a maximum distance of 15 kilometres for a maximum quantity of the organic matrix of about $64 \mathrm{t} / \mathrm{kW}$ (composed partly of silage and solid phase separated from the digestate). In the case of a unit cost of 3 euro/t, the expense per unit of electricity produced is equal to:

Transport: (3.00 euro/t $\bullet 64 \mathrm{ton} / \mathrm{kW}) /(333 \mathrm{kWh} / \mathrm{t}$ biomass $\bullet 24 \mathrm{t} / \mathrm{kW}$ silage) $=0.024$ euro $/ \mathrm{kWh}$

6) the construction costs of a plant are normally expressed in euro per $\mathrm{kW}$ of installed power. The market is currently oriented to values between 3,500 and 4,500 euro/kW for plants with a capacity up to 1 MW powered primarily by dedicated crops, and 7/8,000 euro/kW for small plants $(\sim 100 \mathrm{~kW})$ powered by mostly by manure.

7) the annual cost of operating a plant is mainly composed of: ordinary operating and maintenance costs, annual loan repayments and annual depreciation of capital. As a result, the highest value relates to a $100 \mathrm{~kW}$ plant, for which it an estimated a unit expense of more than 7,000 euro/ $\mathrm{kW}$ is assumed and external financing for $80 \%$ of the capital invested. For the $999 \mathrm{~kW}$ plant, on the other hand, a cost of approximately 4,000 euro/ $\mathrm{kW}$ is expected.

\section{Plant management and operating cost}

As is well known, the management of an anaerobic digestion plant requires special attention, above all, to ensure continuous operation in 
order to achieve high annual production of electricity: an outline time objective of 8,000 hours per year could be assumed. Undoubtedly, attaining this result is only viable if the biological, chemical, technical and mechanical aspects that govern the plant are carefully controlled.

It is, difficult to indicate a value for average expenditure, even if it can be assumed that the unit cost will increase as the installed power decreases, due to the presence of fixed costs that are difficult to eliminate. Therefore, for management expense items we used the same scalar approach as followed for implementation costs: the basic reference figure relates to the management of a plant with a capacity of 999 $\mathrm{kW}$ : it is estimated that this would require annual expenditure of approximately 0.030 euro/kWh of electricity produced, which is equivalent to a total amount of about 243 euro/ $\mathrm{kW}$ per unit of power and approximately 243,000 euro in total.

\section{Finance costs}

The financial costs relate to external financing: the amount is proportional to the capital required, the duration and the rate of interest. For the purposes of calculation, it was assumed that the entrepreneur would rely on an outside agency to obtain financing equal to $80 \%$ of the total investment, with difference provided by the entrepreneur. For the share of external capital, the time assumed for return of capital to the funding entity is 20 years at a rate of $5.0 \%$, while the owner's capital is allocated in a linear fashion during years in which the incentive rate is provided.

\section{Common management costs of the agricultural business}

It was considered appropriate, for the purposes of evaluation, to allocate part of the administration and management costs of the traditional farm enterprise to the management of the biogas plant. In fact, we assumed the project for the digester to be complementary to the agricultural activity, and a portion of more directly agricultural personnel and operating costs would be addressed to this new productive activity. Specifically, we assumed the need at least for an administrative check of about an hour a day and an amount equal to $1 \%$ of the value of the plant for management thereof by the employees of the farm.

At this point we have the necessary values to set up the dynamics of the total management cost of a plant. Based on the assumptions, the total annual management cost for a plant can be estimated to be in a range from a minimum of 0.07-0.08 euro/kWh (for systems of high power capacity) up to $0.15-0.16$ euro/kWh for small installations (Figure 4).

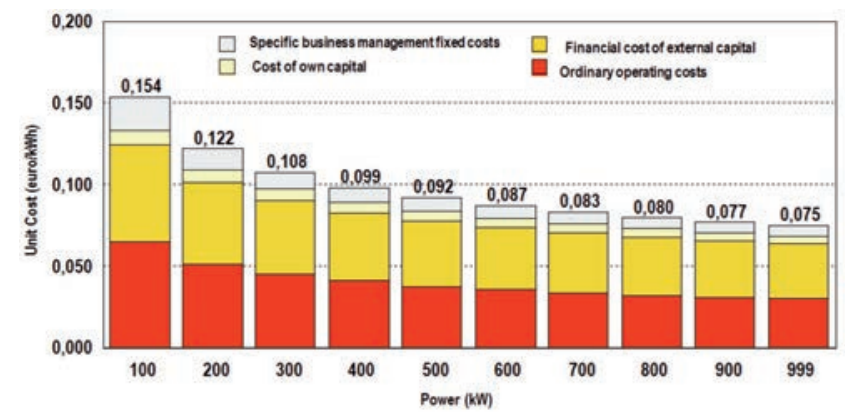

Source: our calculations through direct surveys on biogas plants

Figure 4. Dynamics of the management cost a biogas production plant with increasing power capacity.
The decrease in annual running costs is mainly due to the high initial outlay for the construction of the low power plants, which is reflected in an increase in the financial costs related to the issuing of the loan. Therefore, the management of small installed power capacities (for example, $<100 \mathrm{~kW}$ ) must be suitably balanced with a supply of biomass at very low cost, such as the use of biological raw material (for example, manure or waste of agricultural origin), and only a very small proportion of silage.

\section{Risk analysis: comparison between incentive rates before and after 2012}

The incentive rate for the production of renewable electricity must be properly compared with the costs described above; the main objective here is to compare the two situations prevailing before and after 2012 , when this radical change in the single incentive rate of 0.28 euro/kWh ended 31 December 2012 (Figure 5); In particular, for following assumptions and constants are assumed for the evaluation:

a) plants included in the model have increasing power capacity from 100 to $999 \mathrm{~kW}$

b) the power diet considered consists of the following:

- biological products: dedicated crops produced on land belonging to the business and external land;

- biological products: manure from the farm plus a possible maximum proportion of $30 \%$ by weight of silage.

c) Cost values for the various scenarios were considered as common: only the value of the incentive rate and the composition of the diet for powering plant are modified.

The results we wish to obtain from the simulations have a dual purpose: in the first case, concerning the single rate equal to $0.28 \mathrm{euro} / \mathrm{kWh}$, to confirm the behaviour of the entrepreneurs held in choosing to install mainly high power plants $( \pm 999 \mathrm{~kW})$ powered with dedicated crops, and for the new incentive scheme, to identify some strategies that must be followed to achieve a satisfactory level of profitability for the enterprise. Some more detailed clarifications on the results obtained are outlined below.

(A) Plants with increasing power (100 to $999 \mathrm{~kW})$ powered by biological products before 2013

Until 2013, the design of a plant for the production of biogas powered by dedicated crops offered interesting opportunities for entrepreneurs,

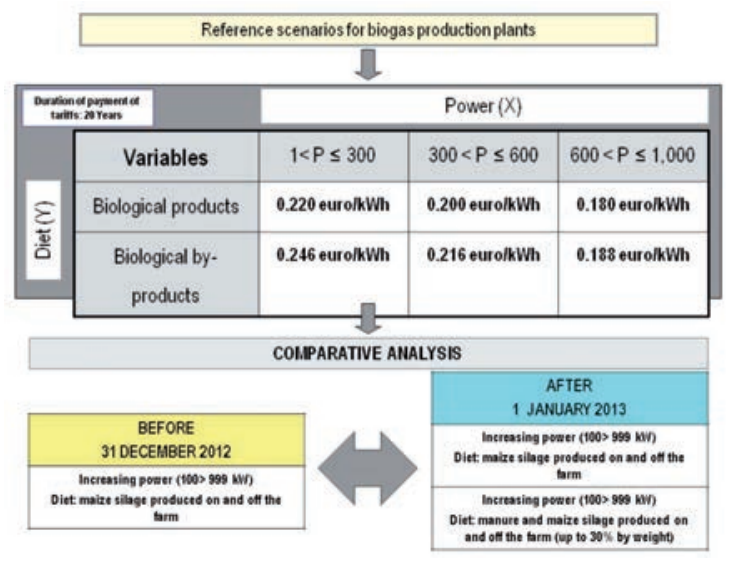

Figure 5. Reference scenarios for the analysis. 
especially in the case where they had the entire surface area available necessary to provide silage for the installed power (Figure 6).

As you can see, the absolute growth in profitability was due to two main factors:

- the presence of significant economies of scale that are recorded in the costs for construction and operation of the plant with increasing installed power; starting from $250 \mathrm{~kW}$ installed power, the profit started to become very significant;

- the increase in the cost for supply of biomass, in a manner less than proportional to the decrease in the operating costs of the plant; note that in the model a maximum amount of biomass produced externally on rented land of $49 \%$ was assumed.

The results obtained under the "old" incentive scheme led to the construction of a large number of installations with powers around the maximum allowed and, only secondly, to consider procurement of biomass as an equally crucial factor for success; as mentioned several times, this strategy was risky and, in fact, we have recently begun to see tensions in grain markets and, above all, in land rental, which can cause problems for the total management cost of the plant.

(B) Plants with increasing power (100 to $999 \mathrm{~kW}$ ) powered by biological products after 1 January, 2013

The second scenario again considers plants powered by maize silage always with the same cost characteristics as indicated in the previous case, but with revenues enhanced by the incentive rate that began on 1 January, 2013.

The scenario changes dramatically and loses all income opportunities for all installed powers. Indeed, in this specific case, precisely because of the incentive rate that decreases as the power increases, large plants are the most penalized in the overall economic analysis (Figure 7). The opportunity for profit margins does not exist for any installed power. Note, however, that the basic assumptions referred to a portion of leased land: therefore, there cost savings can be achieved if the biomass $s$ completely self-produced, but still with a high degree of risk for the enterprise.
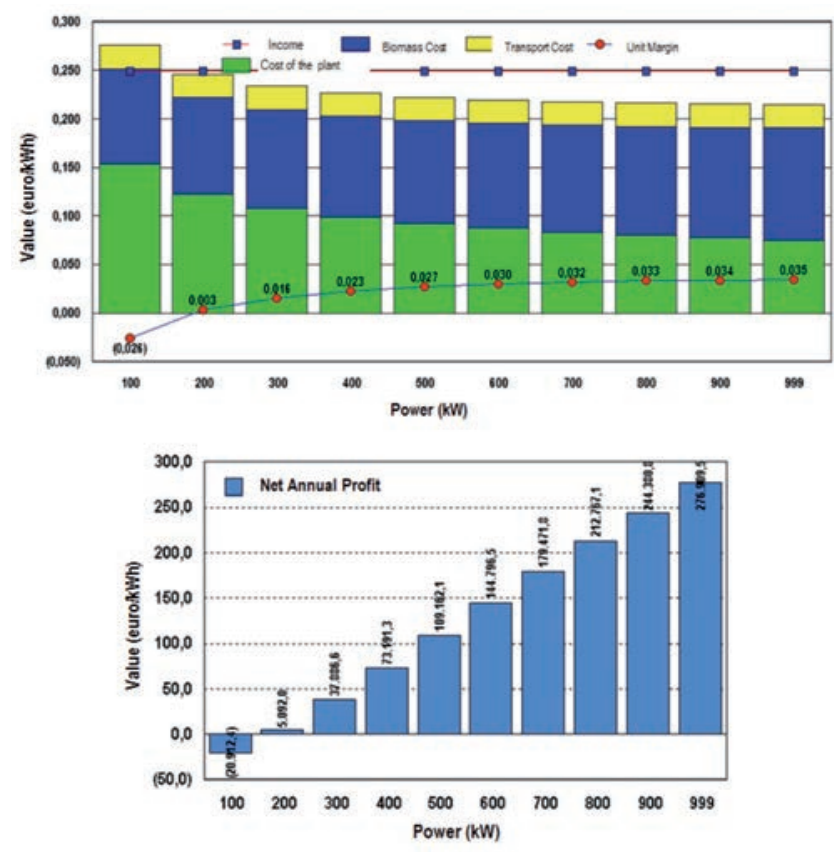

Figure 6. Economic analysis of biogas plants with the incentive rate in force until 31 December 2012.
(C) Plants with increasing power (100 to $999 \mathrm{~kW}$ ) powered by biological by-products after 1 January, 2013

The third scenario takes into consideration plants powered by byproducts with a maximum use of dedicated crops $<30 \%$ by weight. It is assumed that the business has available the manure to be used in the process of feeding the digester. In addition, in the case of power of 100 $\mathrm{kW}$, the diet is composed exclusively of livestock matrix livestock, while as the same power increases, an additional proportion of silage up to a maximum of $30 \%$ by weight was considered, as permitted by the regulations.

In this case, the proposed theoretical operation shows the better operating margins. In fact, the net profit for each installed power is always greater than 0.03 euro/kWh, exceeding 0,05 euro/kWh for plants $<300 \mathrm{~kW}$ (Figure 8).

In absolute terms, it is believed that the most interesting net profit is obtained at two specific points in the growth of the installed power: in fact, around $300 \mathrm{~kW}$ the effect of the higher incentive rate becomes relevant for the first stage. At $600 \mathrm{~kW}$, the high power installed and the corresponding electricity produced, can enhance the profit per unit at 0.04 euro/kWh, although this is lower than the plants with power up to $300 \mathrm{~kW}$.

For the purpose of the evaluation, it was not deemed appropriate to further increase the size of the plants, because it would be necessary to have farms with herds not commonly found in the Italian plains.

\section{Brief concluding remarks}

In conclusion, it can be argued - albeit with the caution we must exercise in processing data of theoretical approaches - that in the future, the entrepreneur will have interesting opportunities for plants with different power capacity in the context of scenarios that use biological products. In addition, the operating margin that can be obtained
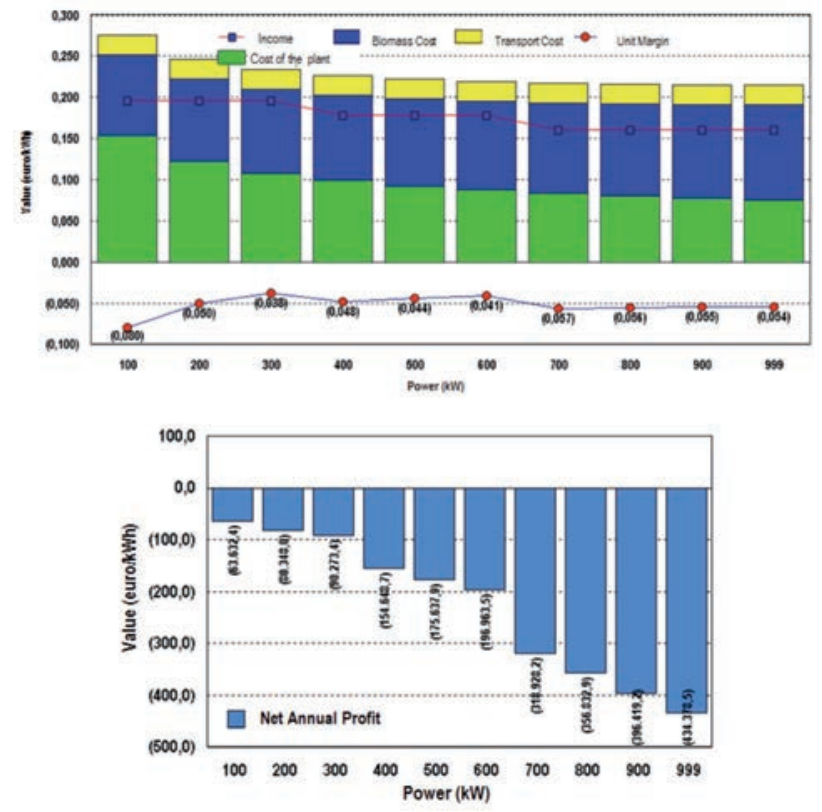

Figure 7. Economic analysis of biogas plants with the incentive rate in force from 1 January, 2013: powered by maize silage. 

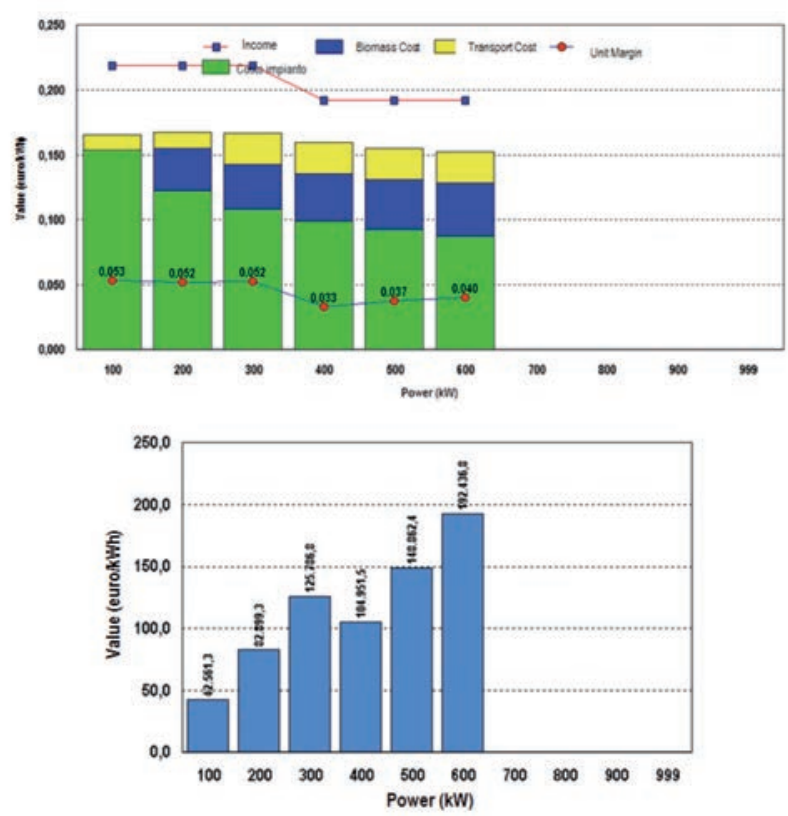

Figure 8. Economic analysis of biogas plants with the incentive rate in force from 1 January, 2013: powered by biological by-products (for example, slurry).

also allows us to consider the possible expensive supply of biomass, in the case where the installed power is to be increased. Conversely, the risks run will be serious if the system is to be powered exclusively with dedicated biomass, especially with cereal silage.

\section{Bibliography}

Balsari, P. (2010), Strategie per la delocalizzazione e l'abbattimento delle emissioni dai reflui zootecnici (Strategies for the relocation and reduction of emissions from manure), Università degli Studi di Torino - TECHNICALDAY "Gestione dei reflui zootecnici: buone pratiche e revisione normativa (Managing manure: good practices and regulatory review)", Carmagnola (T0), 22 June 2010.

Bartonelli V. (2003), Disponibilità di biomassa sul territorio italiano e aspettative reali di sfruttamento (Availability of biomass on the Italian territory and real expectations of exploitation). Il ruolo delle biomasse nell'economia energetica italiana (The role of biomass in the Italian energy economy). in the RECORDS of the APER conference, February, Milano.

Bonari E., Jodice R., Masini S. (2009), L'impresa Agroenergetica: Ruolo e prospettive nello scenario " 2 volte 20 per il 2020" (The Agro-energy Company: Role and prospects in the scenario " 2 times 20 for 2020"), Edizioni Tellus, Rome.

Bonazzi G. Piccinini S. (2005), Nuove strade per smaltire gli effluenti zootecnici (New ways to dispose of manure), Informatore Agrario, no. 7.

Candolo G. (2005). Biomasse vegetali: i possibili processi di conversione energetica (Plant biomass: possible energy conversion processes), Agronomica, no. 4.

Candolo G. (2006). Energia dalle biomasse vegetali: le opportunità per le aziende agricole (Energy from plant biomass: opportunities for farms), Agronomica, no. 4.

A. Castellini, A. Ragazzoni (2009). Giudizio di convenienza per il trattamento dei liquami zootecnici (Findings on the convenience of slurry treatment). Estimo e Territorio, no. 4.

Coiante D. (2010), "Elettricità da biomasse legnose: effetti economici ed ambientali (Electricity from wood biomass: economic and environmental effects)", in www.aspoitalia.it.

Colonna N., Alfano V., Gaeta M. (2009), La stima del potenziale di biogas da biomasse di scarto del settore zootecnico in Italia (Estimate of the potential of biogas from waste biomass of the Italian livestock sector), ENEA, Report RSE 2009/201.

Fabbri C., Piccinini S. (2008). L'analisi di fattibilità per gli impianti di biogas (Feasibility analysis for biogas plants). Agricoltura, no. 36.

Navarotto P. (2010), Limpianto di biogas: tecnologie costruttive e biomasse (The biogas plant: construction technologies and biomass), in Ragazzoni A. (ed.), BIOGAS, come ottenere nuovo reddito per l'agricoltura (BIOGAS, how to obtain new revenue for agriculture), Edizioni Informatore Agrario, Verona.

Piccinini S. (2000), "Interesting prospects for biogas from slurry", Informatore Agrario, no. 13.

Piccinini S., Rossi L. (2007), Sottoprodotti agro-industriali, un potenziale da sfruttare (Agro-industrial by-products, a potential to be exploited), Informatore Agrario, no. 34 .

Ragazzoni A. (2010). Biogas: come ottenere nuovo reddito per l'agricoltura (Biogas: how to obtain new revenue for agriculture). Ed. Informatore Agrario, Verona.

Tiezzi E. (1988), Tempi storici e tempi biologici (Historical times and biological times), in Ceruti M., Laslo E. (ed), "Phisis: Inhabiting the Earth", Feltrinelli, Milano.

Zezza A. (ed.), (2008), Bioenergie: quali opportunità per l'agricoltura italiana (Bioenergy: Opportunities for Italian agriculture), Inea, Edizioni Scientifiche Italiane. 